\title{
Pin1 facilitates NF- $\kappa$ B activation and promotes tumour progression in human hepatocellular carcinoma
}

\author{
Kimio Shinoda ${ }^{1}$, Satoshi Kuboki ${ }^{*}{ }^{1}$, Hiroaki Shimizu ${ }^{1}$, Masayuki Ohtsuka ${ }^{1}$, Atsushi Kato ${ }^{1}$, Hideyuki Yoshitomi ${ }^{1}$, \\ Katsunori Furukawa ${ }^{1}$ and Masaru Miyazaki ${ }^{1}$ \\ ${ }^{1}$ Department of General Surgery, Graduate School of Medicine, Chiba University, Chiba 260-0856, Japan
}

\begin{abstract}
Background: NF- $\kappa \mathrm{B}$ promotes HCC progression; however, therapies targeting NF- $\kappa \mathrm{B}$ are not used due to severe adverse reactions. Pin1 is reported to induce tumour progression in vitro. However, the role of Pin 1 in HCC is unclear. Moreover, little is known about the mechanism of Pin1-mediated NF- $\kappa$ B activation.

Methods: Fresh surgical specimens were collected from 144 HCC patients. Pin1 and NF- $\kappa$ B-p65 expression was evaluated by immunohistochemistry and western blotting. NF- $\kappa \mathrm{B}$ activation was assessed by EMSA.

Results: Pin 1 was increased in HCC compared to adjacent liver tissue. The multivariate analysis revealed that high Pin 1 expression was an independent factor for poor prognosis. In HCC with high Pin1 expression, tumour size was larger and portal vein invasion was increased. Pin1 expression was correlated with phosphorylated ( $p-$ ) NF- $\kappa$ B-p65(Thr254) and p-NF- $k B-p 65($ Ser276), and thereby NF- $\kappa$ B activation. Pin1-induced NF- $\kappa$ B activation accelerated cell cycle progression, induced angiogenesis, and inhibited apoptosis. Pin1 knockdown in HCC cells inhibited the phosphorylation of NF- $\kappa$ B-p65(Ser276), and reduced NF- $\kappa$ B activation, which resulted in inhibiting tumour cell progression. When HCC cells were treated with the Pin1 inhibitors, p-NF- $\kappa$ B-p65(Ser276) expression and NF- $\kappa \mathrm{B}$ activation was reduced, and cell proliferation was inhibited.
\end{abstract}

Conclusions: Pin 1 is associated with aggressive tumour progression and poor prognosis in $\mathrm{HCC}$ by mediating NF- $\kappa$ B activation.

Hepatocellular carcinoma (HCC) is the common cause of cancer-related death worldwide (El-Serag, 2011). Despite the fact that multidisciplinary therapy has improved, the prognosis of advanced HCC is still poor. Therefore, it is urgent to reveal the mechanisms of HCC progression, to identify potent prognostic factors, and to discover new therapeutic targets for HCC. HCC progression is strongly related to inflammatory responses. Among the factors regulating inflammatory cascades, nuclear factor $\kappa \mathrm{B}$ $(\mathrm{NF}-\kappa \mathrm{B})$ is reported to be essential for promoting HCC progression (Pikarsky et al, 2004). Previous studies have focused on regulating $\mathrm{NF}-\kappa \mathrm{B}$ activation as cancer treatments; however, therapies targeting NF- $\kappa \mathrm{B}$ are not widely used due to severe adverse reactions, as complete deletion of NF- $\kappa \mathrm{B}-\mathrm{p} 65$ induces severe cellular apoptosis in normal tissues (Beg et al, 1995).
Therefore, the development of a new therapeutic target controlling $\mathrm{NF}-\kappa \mathrm{B}$ activation is essential to improve the prognosis of HCC.

The phosphorylation of Ser/Thr residues is important for activating the functions of proteins. The peptidyl-prolyl cis-/transisomerase, Pin1, binds to phosphorylated $(\mathrm{p}-$ ) Ser/p-Thr residue in target proteins and induces conformational changes following phosphorylation to regulate protein function ( $\mathrm{Lu}$ et al, 2002). It has been reported that Pin 1 is overexpressed in many cancers, including breast cancer (Ryo et al, 2003), prostate cancer (Ayala et al, 2003), glioblastoma (Atkinson et al, 2009), and HCC (Pang et al, 2004; Pang et al, 2007; Cheng et al, 2013). Pin1 has been shown to mediate NF- $\kappa \mathrm{B}$ activation; however, only a few studies have revealed a direct interaction between Pin 1 and NF- $\kappa$ B-p65. It has been reported that Pin 1 specifically binds to the 
p-NF- $\kappa \mathrm{B}$-p65(Thr254), inhibits its binding to $\mathrm{I} \kappa \mathrm{B} \alpha$, induces the translocation of Pin1-NF- $\kappa \mathrm{B}-\mathrm{p} 65$ complex to the nucleus and enhances its stability in HeLa cells in vitro (Ryo et al, 2003). We have previously reported that Pin 1 protects hepatocytes from ischaemic liver injury by increasing NF- $\kappa \mathrm{B}$ activation through the production of Pin1-NF- $\kappa$ B-p65 complex (Kuboki et al, 2007; Kuboki et al, 2009). In HCC, Pin1 is known to interact with hepatitis $\mathrm{B}$ virus $\mathrm{X}$ protein, beta-catenin, or survivin to enhance carcinogenesis and tumour progression. However, no reports have revealed an interaction between Pin 1 and NF- $\kappa$ B in HCC in any experimental models. Moreover, there have been no investigations which focus on the relationship between Pin1 expression and clinicopathological features or prognosis in patients with HCC.

The aim of this study was to evaluate the expression of Pin 1 in patients with HCC in order to investigate the correlations with clinicopathological variables, including patient survival, and to determine whether Pin1-mediated NF- $\kappa \mathrm{B}$ activation is a relevant factor in the regulation of HCC progression.

\section{MATERIALS AND METHODS}

Tissue samples. We studied 144 HCC patients who underwent primary curative surgical resection between 2000 and 2008 at our institution. None of the patients received preoperative treatments. Patients with extrahepatic metastasis before operation were excluded from this study. Fresh surgical specimens were obtained from these patients during operation. Normal liver tissues were obtained from 10 patients with liver metastases of colorectal cancer (controls). Portions of the samples were fixed in formalin, embedded in paraffin, and stained with hematoxylin-eosin. The classification proposed by the Liver Cancer Study Group of Japan was used for evaluating the pathological features of HCC (The liver cancer study group of Japan, 2011). The degree of liver fibrosis was assessed by Metavir score, and F2 or more was defined as the presence of liver fibrosis, and F4 as the presence of liver cirrhosis. Nuclear extracts and whole tissue lysates were extracted from 32 HCC samples and 10 normal liver samples. Fully informed consent was obtained from all patients. The study was performed in accordance with the guidelines of the Helsinki Declaration of 1975, as amended in 1983, and approved by Chiba University Human Research Committee.

Immunohistochemical staining. Immunohistochemical staining was performed with anti-Pin1, anti-p-NF- $\kappa$ B-p65(Thr254), anti-pNF- $\kappa$ B-p65(Ser276) (Santa Cruz Biotechnology, Santa Cruz, CA, USA), anti-CD34, or anti-Ki-67 antibody (Dako, Copenhagen, Denmark) using the EnVision Kit or Universal LSAB Kit (Dako), and was counterstained with hematoxylin. Pin1 expression was evaluated using the Image $\mathrm{J}$ based on the staining intensity and percentage of positive cells. For the intensity, the grading scale ranged from 0 (no signal), to 1 (very weak signal), 2 (weak signal), 3 (moderate signal), 4 (strong signal), and 5 (the strongest signal). The intensity grade was evaluated by two independent clinical pathologists and the total score was recognised as the Pin1 intensity score $(0-10)$. The percentage value for the positive cells was divided by 10 and determined as the Pin 1 percentage score $(0-10)$. The total of the intensity score and the percentage score was defined as the Pin1 labelling index (0-20). The cell proliferation index by Ki-67 and the microvessel density (MVD) levels by CD34 were determined according to the method described in previous studies (Mitsuhashi et al, 2003; Aigelsreiter et al, 2013). Determination of p-NF- $\kappa \mathrm{B}-\mathrm{p} 65$ labelling index was evaluated by immunohistochemistry based on the percentage of positive nuclei, and was expressed as the labelling index of HCC. TUNEL staining was performed in accordance with the manufacture's instruction using the TUNEL staining kit (Dako).
Western blotting. Western blotting was done using whole tissue lysates or whole cell lysates, as previously described (Kuboki et al, 2009). Tris-buffered saline with dry milk or PhosphoBLOCKER (Cell Biolabs Inc., San Diego, CA, USA) were used for blocking non-specific binding sites. Antibodies against $\mathrm{Pin} 1, \mathrm{I} \kappa \mathrm{B} \alpha$, NF- $\kappa$ B-p65, p-NF- $\kappa$ B-p65(Thr254), p-NF- $\kappa$ B-p65(Ser276), Cyclin D1, cyclin-dependent kinases regulatory subunit 1 (Cks1), p27(kip1), vascular endothelial growth factor (VEGF) or $\beta$-actin (Santa Cruz Biotechnology) were used for primary antibody. Immunoreactive proteins were detected by enhanced chemiluminescence and quantified by image analysis.

Electrophoretic mobility shift assay. Nuclear extracts were analysed by electrophoretic mobility shift assay (EMSA), as previously described (Kuboki et al, 2009). Briefly, double-stranded consensus oligonucleotides to NF- $\kappa \mathrm{B}$ (Promega Corporation, Madison, WI, USA) were end-labelled with $\gamma\left[{ }^{32} \mathrm{P}\right]$ ATP (Perkin Elmer Inc. Boston, MA, USA). Binding reaction products of NF- $\kappa$ B were separated in a polyacrylamide gel and analysed by autoradiography.

Cell culture. HepG2 cells and HuH-7 cells, from the Health Science Research Resources Bank (Osaka, Japan), were distributed onto 6-well plates (Asahi Techno Glass, Tokyo, Japan) at a concentration of $1.5 \times 10^{4}$ cells per $3 \mathrm{ml}$ per well in Dulbecco's modified Eagle medium (Sigma-Aldrich, St. Louis, MO, USA). After overnight incubation, Pin1-specific small interfering RNA (siRNA) or negative control siRNA was transfected into HCC cells using HiPerFect Transfection Reagent (QIAGEN Inc., Valencia, CA, USA). These cells were further treated with $10 \mathrm{ng} \mathrm{ml}^{-1}$ tumour necrosis factor- $\alpha(\mathrm{TNF} \alpha)$ for $30 \mathrm{~min}$ to activate NF- $\kappa \mathrm{B}$. In some experiments, cells were incubated for 24,48 or $72 \mathrm{~h}$ in medium containing 0 (vehicle only), 5, 10, 25 or $50 \mu \mathrm{moll}^{-1}$ juglone or PiB (Sigma-Aldrich). Cell proliferation was evaluated at $48 \mathrm{~h}$ after treatment by DNA incorporation of 5-bromo-2'deoxyuridine (BrdU) using the Biotrak cell proliferation ELISA system (GE Healthcare, Buckingham, UK). For cell cycle analysis, cells were harvested and suspended with PBS containing $100 \mu \mathrm{g} \mathrm{ml}^{-1}$ propidium ionide and $10 \mu \mathrm{g} \mathrm{ml}^{-1} \mathrm{RNase}$, and analysed the content of DNA using BD FACS CANTO II (BD Biosciences, Franklin Lakes, NJ, USA). Cell invasiveness was evaluated at $48 \mathrm{~h}$ after treatment using the Cell Invasion Assay Kit (Cell Biolabs Inc.). Cell lysates and nuclear extracts were prepared for western blotting or EMSA.

Statistical analysis. Data are expressed as means \pm s.e.m. Statistical comparisons for significance were performed using Student's $t$-test or the Mann-Whitney $U$-test. Kaplan-Meier method was used for estimating survival, and statistical differences were analysed by the log-rank test. Significant prognostic factors evaluated by univariate logistic regression were included in a multivariable analysis to determine independent factors for poor prognosis. Probability $(P)$ values of 0.05 or less were considered to be statistically significant. Statistical analyses were performed using the software JMP 11 (SAS Institute Inc., Cary, NC, USA).

\section{RESULTS}

Pin1 expression in normal liver tissue, adjacent liver tissue, and HCC. Immunohistochemical staining showed that Pin1 was expressed at low levels in normal liver tissue (Figure 1A), and adjacent liver tissue (Figures $1 \mathrm{~B}$ and $\mathrm{C}$ ). Increased expression of Pin1 was seen in some cases of HCC compared to adjacent liver tissue (Figure 1B), but not in other cases of HCC (Figure 1C).

Clinical significance of Pin1 expression. A training set with 106 HCC patients from 2003 to 2008 were divided into two groups based on the Pin1 labelling index in HCC, low Pin1 expression and high Pin1 expression. Receiver operating characteristic (ROC) 
A

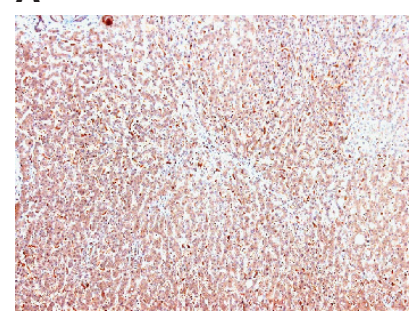

$\mathrm{NL}$

D

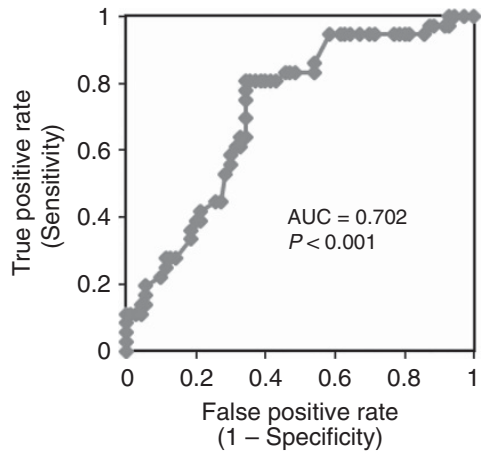

F

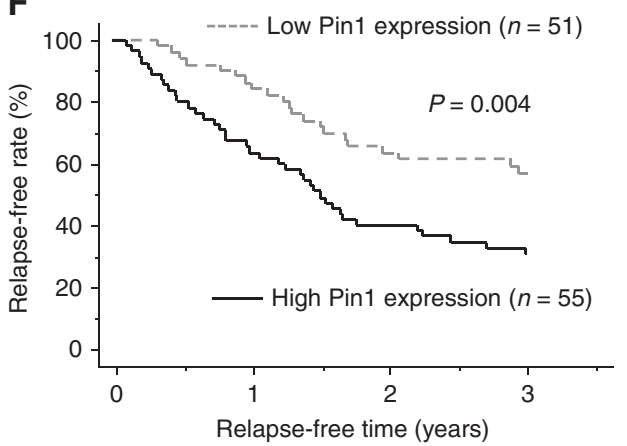

B

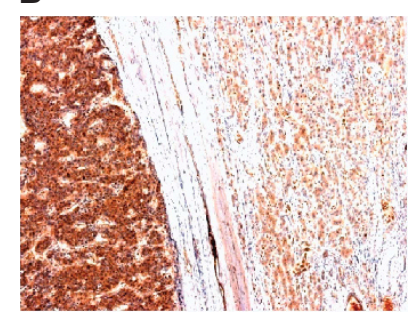

$\mathrm{HCC} / \mathrm{NT}$

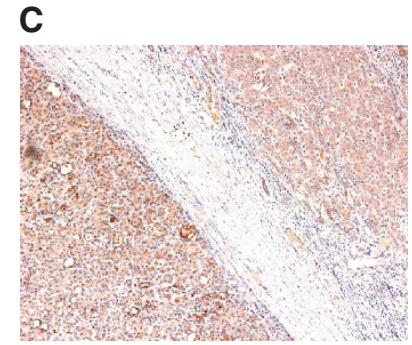

$\mathrm{HCC} / \mathrm{NT}$

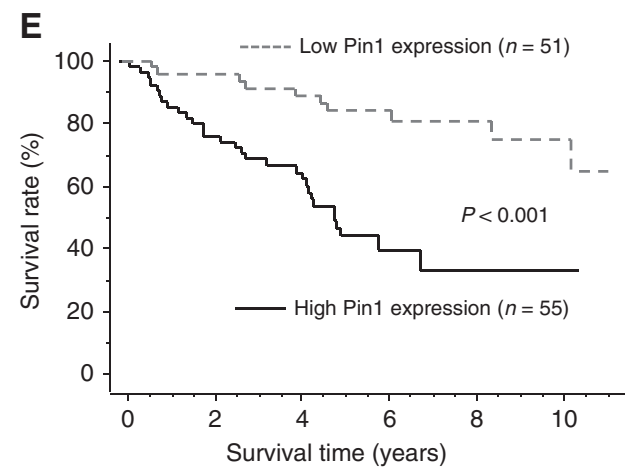

G

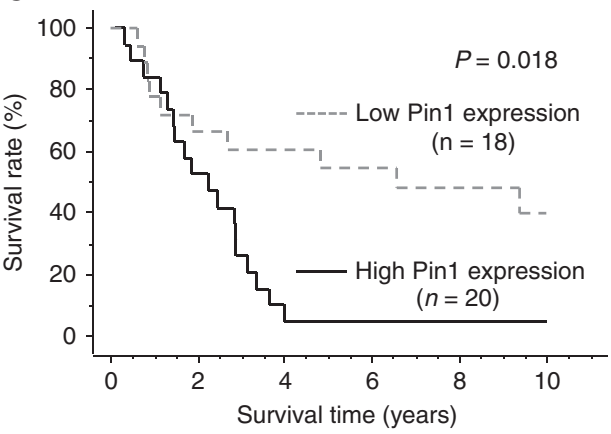

Figure 1. Immunohistochemical staining for Pin1 in (A) normal liver tissues from patients with liver metastasis (NL), (B) HCC with high Pin1 expression and adjacent non-tumorous liver tissue (NT), and (C) HCC with low Pin1 expression and NT. Results are representative of 10-55 sections. (D) ROC curve analysis of Pin1 labelling index in accordance with the 5-year survival. (E) Overall survival and (F) relapse-free survival of $106 \mathrm{HCC}$ patients in relation to Pin1 expression in HCC analysed by the Kaplan-Meier methods. (G) Overall survival of 38 HCC patients in the validation set were analysed by the Kaplan-Meier methods to validate the effectiveness of Pin1 labelling index as a predictor for poor prognosis.

revealed that the adequate cutoff value of Pin1 labelling index in accordance with the 5-year survival was 7.5 (Figure 1D). The accuracy was relatively high, as the area under the curve was 0.702 . When the relationships between Pin1 expression in HCC and several clinicopathological variables were evaluated, the frequency of female gender $(P=0.023)$, positive tumour capsule $(P=0.021)$, larger tumour size $(P=0.024)$, and positive portal vein invasion $(P=0.045)$ were significantly higher in patients with high Pin1 expression than those with low Pin 1 expression (Supplementary Table S1). Pin1 had no significant correlations with the background liver diseases such as viral infection, hepatic steatosis, or liver cirrhosis. An analysis with the Kaplan-Meier method revealed that overall survival time for patients with high Pin1 expression was significantly poorer when compared with those with low Pin1 expression $(P<0.001$, Figure $1 \mathrm{E})$. The univariate and multivariate analyses revealed that the presence of intrahepatic metastasis $(P<0.001)$, pathological poorly differentiation $(P=0.003)$, and high Pin1 expression in HCC $(P<0.001)$ were independent prognostic factors associated with overall survival (Table 1). In addition, early recurrence rate within 3 years was significantly higher in patients with high Pin1 expression in HCC $(P=0.004$,
Figure $1 \mathrm{~F}$ ). When type of initial recurrence after hepatectomy was evaluated, the incidence of local (intrahepatic) recurrence was significantly higher in patients with high Pin 1 expression. Patients with high Pin1 expression seemed to show increased distant (extrahepatic) metastasis at the time of recurrence; however, not statistically significant (Supplementary Table S1). Moreover, the presence of intrahepatic metastasis $(P=0.045)$, the presence of portal vein invasion $(P=0.037)$, and high Pin1 expression in HCC $(P=0.006)$ were independent factors associated with early recurrence in HCC after hepatectomy (Supplementary Table S2). To confirm the effectiveness of Pin1 labelling index in HCC as a predictor for poor prognosis, 38 HCC patients from 2000 to 2002 were investigated as a validation set. The cutoff value of Pin 1 labelling index, 7.5, was used to divide these patients into high and low Pin1 groups. Consistent with the results in the training set, HCC patients with high Pin1 expression showed significant poorer prognosis than those with low Pin1 expression in the validation set $(P=0.018$, Figure $1 \mathrm{G})$.

Pin1 facilitates NF- $\kappa$ B activation in HCC. For further analyses, 106 HCC samples from the training set were evaluated. EMSA 
results revealed that no significant differences were seen in NF- $\kappa \mathrm{B}$ activation among normal liver tissue, adjacent liver tissue, and HCC with low Pin1 expression. However, NF- $\kappa$ B activation was significantly increased in HCC with high Pin1 expression
(Figure 2A). NF- $\kappa \mathrm{B}$ activation was correlated with Pin1 expression evaluated by western blotting $(P=0.038$, Figure $2 \mathrm{~B})$. As Pin1 has been reported to recognise the p-Thr254-Pro motif in NF- $\kappa \mathrm{B}-\mathrm{p} 65$, the nuclear accumulation of $\mathrm{p}-\mathrm{NF}-\kappa \mathrm{B}-\mathrm{p} 65(\mathrm{Thr} 254)$ was evaluated

Table 1. Univariate and multivariate analyses of survival in 106 patients with HCC

\begin{tabular}{|c|c|c|c|c|}
\hline & \multicolumn{2}{|c|}{ Univariate analysis } & \multicolumn{2}{|c|}{ Multivariate analysis } \\
\hline & Hazard ratio & $P$-value & Hazard ratio & $P$-value \\
\hline Age $(\geqslant 70, n=47$ vs $<70, n=59)$ & $1.192(0.636-2.232)$ & 0.583 & & \\
\hline Gender (female, $n=26$ vs male, $n=80$ ) & $1.480(0.751-2.917)$ & 0.257 & & \\
\hline Fibrosis (F2-4, $n=56$ vs F0, $n=50$ ) & $1.240(0.666-2.309)$ & 0.498 & & \\
\hline Cirrhosis (F4, $n=29$ vs F0-3, $n=77$ ) & $1.060(0.518-2.170)$ & 0.874 & & \\
\hline ICG-15R $(\geqslant 15 \%, n=43$ vs $<15 \%, n=63)$ & $1.100(0.590-2.053)$ & 0.764 & & \\
\hline Tumour size ( $\geqslant 50 \mathrm{~mm}, n=63$ vs $<50 \mathrm{~mm}, n=43)$ & $3.047(1.605-5.783)$ & $<0.001^{*}$ & $1.805(0.718-4.539)$ & 0.210 \\
\hline Tumour capsule (absent, $n=19$ vs present, $n=87$ ) & $5.310(1.279-22.047)$ & $0.022^{*}$ & $4.197(0.817-21.563)$ & 0.086 \\
\hline Capsule infiltration (present, $n=66$ vs absent, $n=40$ ) & $2.403(1.143-5.052)$ & $0.021 *$ & $1.296(0.503-3.338)$ & 0.591 \\
\hline Septum formation (present, $n=82$ vs absent, $n=26$ ) & $1.183(0.563-2.487)$ & 0.657 & & \\
\hline Number of the tumour (multiple, $n=21$ vs solitary, $n=85$ ) & $2.530(1.280-4.998)$ & $0.008^{*}$ & $1.033(0.332-3.208)$ & 0.956 \\
\hline Intrahepatic metastasis (present, $n=30$ vs absent, $n=76$ ) & $3.412(1.818-6.404)$ & $<0.001^{\star}$ & $6.225(2.149-18.030)$ & $<0.001^{*}$ \\
\hline Portal vein invasion (positive, $n=40$ vs negative, $n=66$ ) & $3.443(1.822-6.508)$ & $<0.001^{*}$ & $1.289(0.564-2.946)$ & 0.547 \\
\hline Venous invasion (positive, $n=5$ vs negative, $n=101$ ) & $2.774(0.846-9.104)$ & 0.092 & & \\
\hline Serosal infiltration (present, $n=13$ vs absent, $n=93$ ) & $2.054(0.905-4.664)$ & 0.085 & & \\
\hline Differentiation (poorly, $n=7$ vs moderately and well, $n=99$ ) & $3.116(1.097-8.849)$ & $0.033^{*}$ & $6.324(1.859-21.514)$ & $0.003^{*}$ \\
\hline PIVKA-II ( $\geqslant 80 \mathrm{mAU} \mathrm{m}^{-1}, n=55$ vs $\left.<80 \mathrm{mAU} \mathrm{m}^{-1}, n=51\right)$ & $2.153(1.110-4.176)$ & $0.023^{*}$ & $1.840(0.833-4.607)$ & 0.132 \\
\hline $\operatorname{AFP}\left(\geqslant 40 \mathrm{ng} \mathrm{ml}^{-1}, n=45\right.$ vs $\left.<40 \mathrm{ng} \mathrm{ml}^{-1}, n=61\right)$ & $1.125(0.592-2.139)$ & 0.720 & & \\
\hline Pin1 expression in HCC (high, $n=55$ vs low, $n=51$ ) & $4.252(2.028-8.916)$ & $<0.001^{\star}$ & $5.285(2.290-12.198)$ & $<0.001^{*}$ \\
\hline
\end{tabular}

A

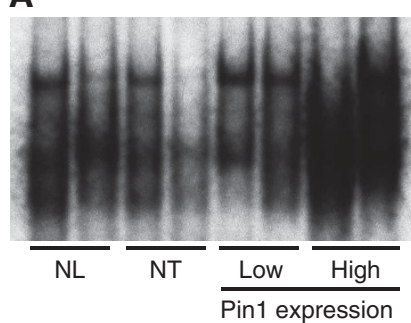

in HCC

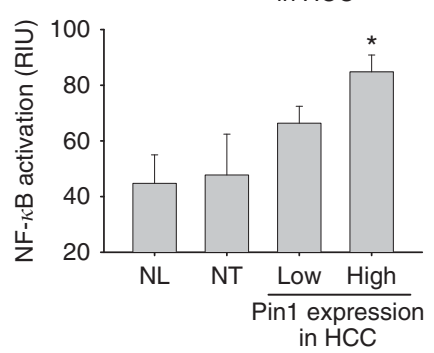

E

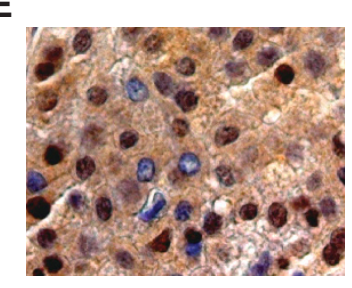

B
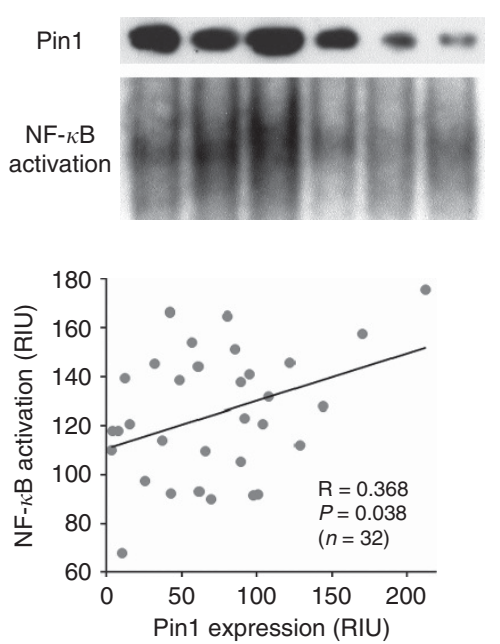

$\mathbf{F}$

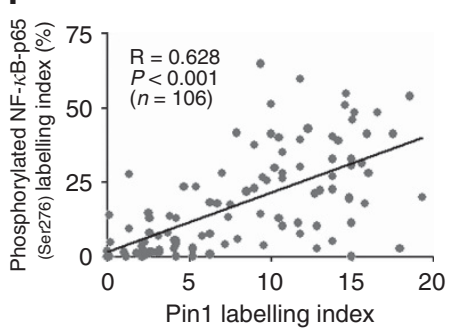

C

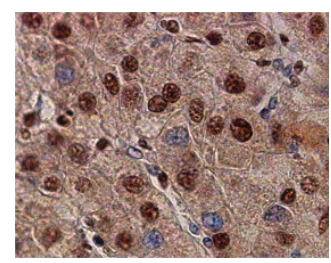

D

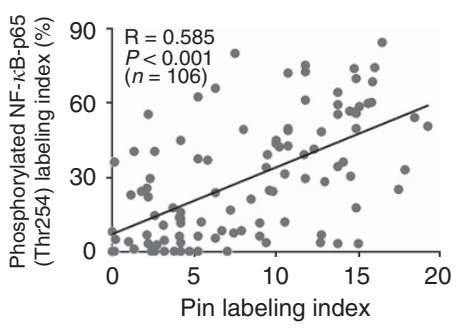

G

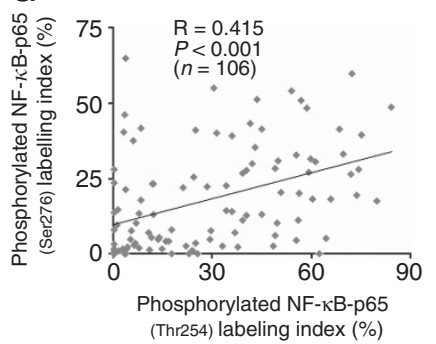

Figure 2. (A) NF- $\kappa$ B activation in normal liver tissues from patients with liver metastasis (NL), adjacent non-tumorous liver tissue (NT), and HCC with low and high Pin1 expression, analysed by EMSA. Results were quantitated by image analysis of autoradiograms. Data are means \pm s.e.m. with $n=10-32$ per group. ${ }^{*} P<0.01$ compared with NL, NT, and HCC with low Pin1 expression. (B) A correlation between Pin1 expression by western blotting and NF- $\kappa$ B activation by EMSA. Nuclear accumulation of (C) p-NF- $\kappa$ B-p65(Thr 254) or (E) p-NF- $\kappa$ B-p65(Ser276) was evaluated by immunohistochemical staining. Results are representative of $106 \mathrm{HCC}$ sections. A significant correlation was seen between Pin1 labelling index and (D) the p-NF- $\kappa$ B-p65(Thr 254) labelling index or (F) the p-NF- $\kappa$ B-p65(Ser276) labelling index. (G) A significant correlation was found between p-NF- $\kappa$ B-p65(Thr 254) labelling index and p-NF- $\kappa$ B-p65(Ser276) labelling index. 
by immunohistochemistry (Figure $2 \mathrm{C}$ ). Interestingly, the $\mathrm{p}-\mathrm{NF}-\kappa \mathrm{B}$ p65(Thr254) labelling index was significantly correlated with Pin1 expression $(P<0.001$, Figure 2D). After binding to the $\mathrm{p}$-Thr254Pro motif in NF- $\kappa \mathrm{B}-\mathrm{p} 65$, Pin 1 has been reported to induce the phosphorylation of the Ser276 motif in NF- $\kappa$ B-p65 to mediate its DNA binding. As shown in Figure 2E, the nuclear accumulation of p-NF- $\kappa$ B-p65(Ser276) was seen in some HCC cells. Consistent with the EMSA results, the p-NF- $\kappa \mathrm{B}-\mathrm{p} 65$ (Ser276) labelling index, an indicator of Pin1-induced NF- $\kappa \mathrm{B}$ activation, was significantly correlated with Pin1 expression $(P<0.001$, Figure $2 \mathrm{~F})$. Moreover, the p-NF- $\kappa \mathrm{B}-\mathrm{p} 65$ (Ser276) labelling index correlated with the p-NF- $\kappa$ B-p65(Thr 254) labelling index $(P<0.001$, Figure $2 \mathrm{G})$.

Pin1-induced NF- $\kappa$ B activation promotes cell proliferation, induces angiogenesis, and inhibits apoptosis in HCC. When the cell proliferation index was determined by Ki-67 immunohistochemistry (Figure $3 \mathrm{~A}$ ), it was positively correlated with the Pin1 labelling index $(P<0.001$, Figure $3 \mathrm{~B})$, the p-NF- $\kappa$ B-p65(Thr254) labelling index $(P<0.001$, Figure $3 \mathrm{C})$, and the $\mathrm{p}-\mathrm{NF}-\kappa \mathrm{B}-$ p65(Ser276) labelling index $(P<0.001$, Figure 3D). To reveal the mechanisms of Pin1-mediated cell cycle progression, involvement of cyclin D1 or Cks1-p27(kip1) pathway was evaluated by western blotting (Figure 3E). Interestingly, cyclin D1 expression was significantly higher in HCC with high Pin1 expression. Moreover, the expression levels of $\mathrm{p} 27$ (kip1), a potent cell cycle inhibitor, was lower in HCC with high Pin1 expression. In contrast, the expression levels of Cks1, which induces the degradation of p27(kip1), were higher in HCC with high Pin1 expression. A significant correlation was found between Pin1 expression and the MVD levels as assessed by CD34 immunohistochemistry $(P<0.001$, Figures $3 \mathrm{~F}$ and $\mathrm{G})$. Number of apoptotic cells assessed by TUNEL staining was significantly higher in HCC with low Pin1 expression than those with high Pin1 expression $(P=0.002$, Figures $3 \mathrm{H}$ and $\mathrm{I}$ ).

Effects of Pin1 knockdown on HCC cells in vitro. Knockdown of Pin 1 by its siRNA significantly inhibited the expression of p-NF$\kappa \mathrm{B}-\mathrm{p} 65$ (Thr254) and p-NF- $\kappa \mathrm{B}-\mathrm{p} 65($ Ser276), thereby reducing the activity of NF- $\kappa$ B in HepG2 cells (Figure 4A). Activation of NF- $\kappa$ B after TNF $\alpha$ treatment was significantly inhibited in Pin 1 knockdown cells when compared with negative controls, suggesting the direct interaction of Pin 1 with NF- $\kappa$ B. Pin 1 depletion significantly decreased cyclin D1 expression and increased p27(kip1) expression. However, Pin1 knockdown had no effects on the expression of $\mathrm{I} \kappa \mathrm{B} \alpha, \mathrm{p} 65$, or Cks1. Moreover, VEGF expression was decreased in HepG2 cells with Pin1 knockdown. DNA incorporation of BrdU was reduced in Pin 1 knockdown cells after $48 \mathrm{~h}$ of treatment, when compared with negative controls (Figure 4B). Consistent with these
A

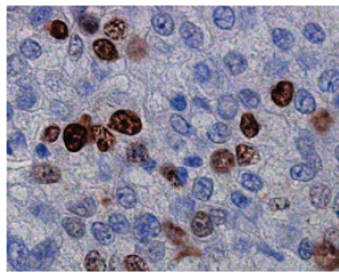

B

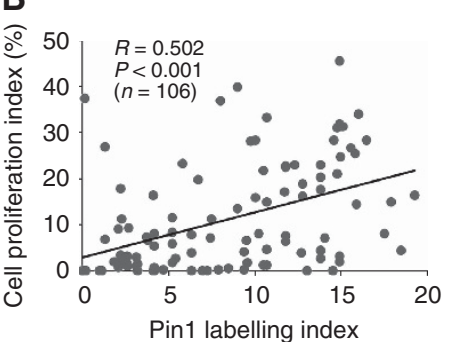

C

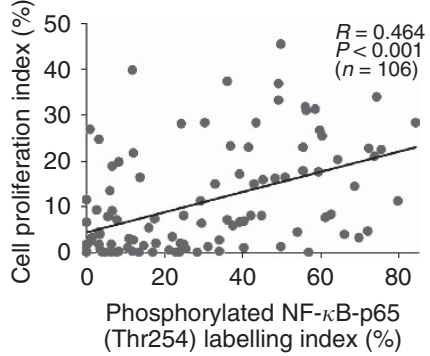

D

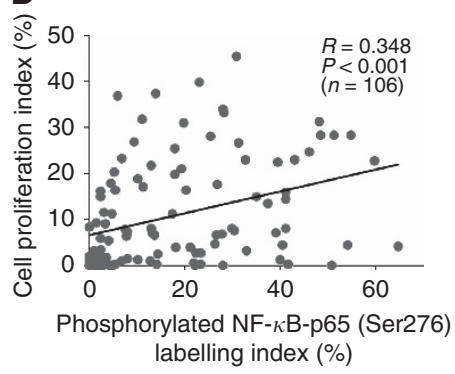

E
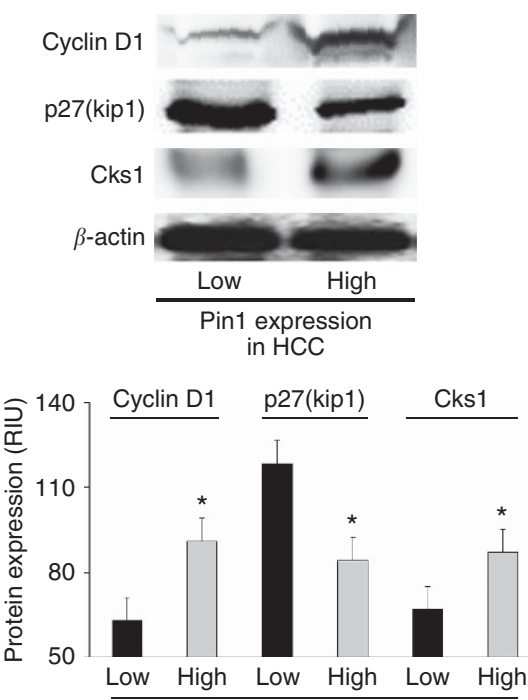

Pin1 expression in HCC
$\mathbf{F}$

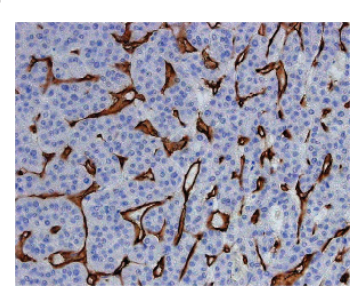

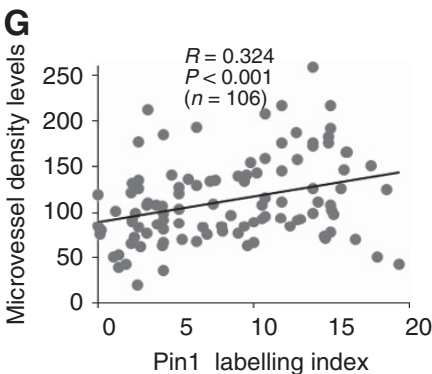

H

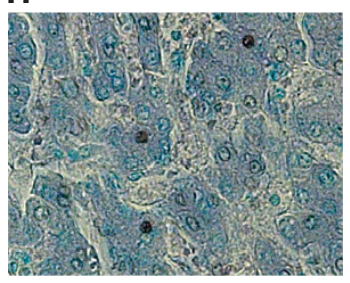

I

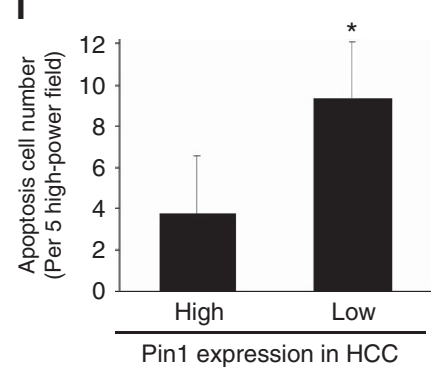

Figure 3. (A) Cell proliferation in HCC determined by immunohistochemical staining for Ki-67. Result is representative of $106 \mathrm{HCC}$ sections. The cell proliferation index of HCC was significantly correlated with (B) Pin1 labelling index, (C) p-NF- $\kappa$ B-p65(Thr 254) labelling index, and (D) p-NF- $\kappa$ B-p65(Ser276) labelling index. (E) The expression levels of Cyclin D1, p27(kip1), and Cks1 evaluated by western blotting.

Chemiluminescence films were quantified by image analysis. Data are means \pm s.e.m. ${ }^{\star} P<0.05$ vs HCC with low Pin 1 expression. (F) Angiogenesis evaluated by CD34 immunohistochemistry. Result is representative of $106 \mathrm{HCC}$ sections. (G) The MVD levels were significantly correlated with Pin 1 expression in HCC. (H) Apoptosis was evaluated by TUNEL staining. Result is representative of $106 \mathrm{HCC}$ sections. (I) Apoptosis was significantly increased in $\mathrm{HCC}$ with low Pin 1 expression. ${ }^{*} \mathrm{P}<0.05$ vs $\mathrm{HCC}$ with high Pin1 expression. 
A

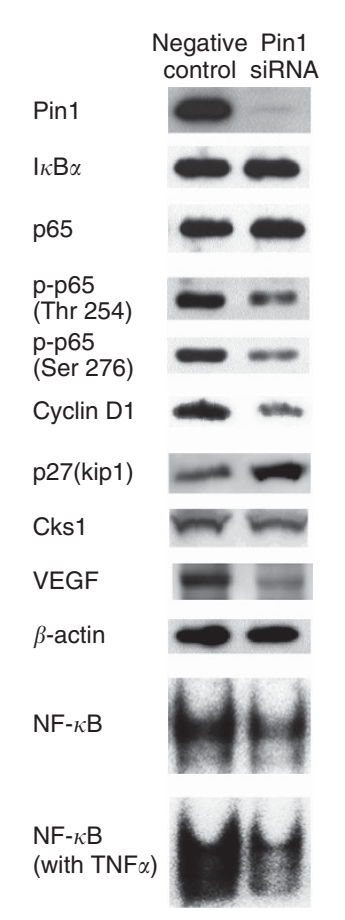

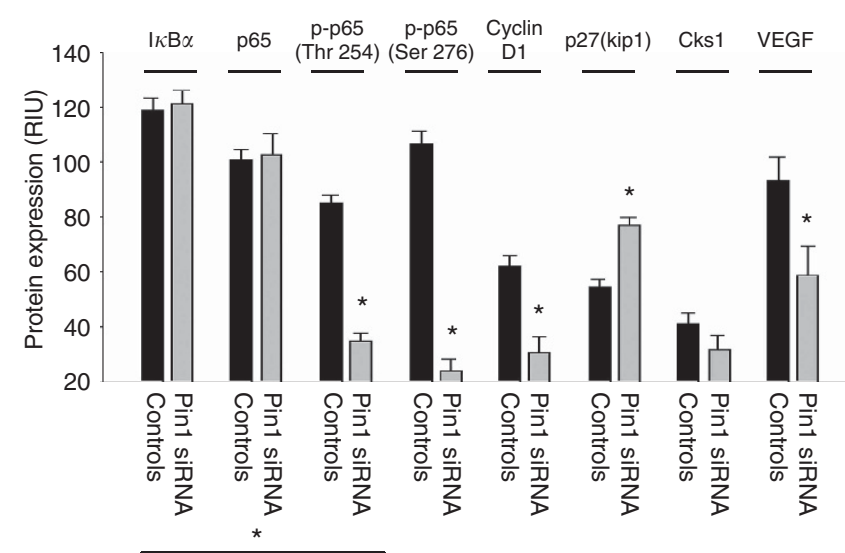

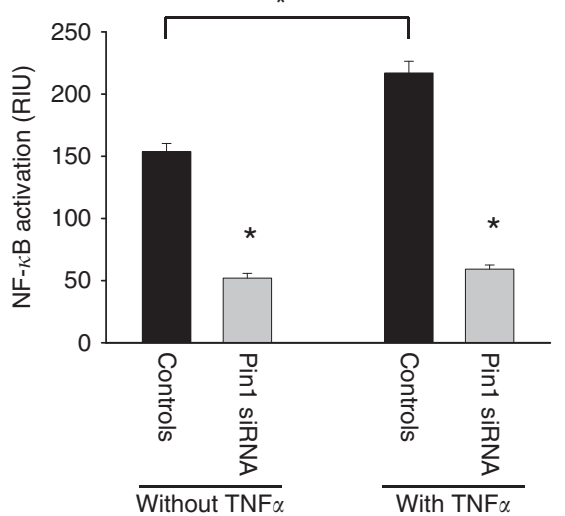

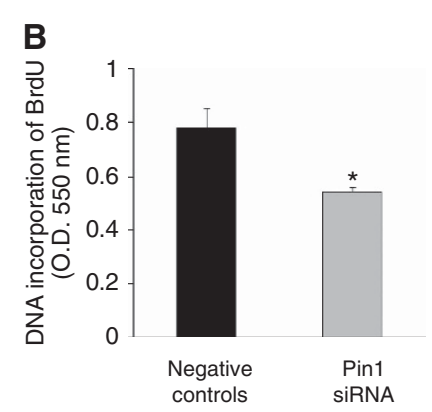

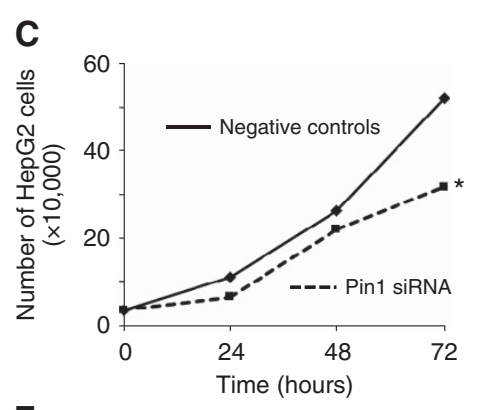

$\mathbf{F}$
D

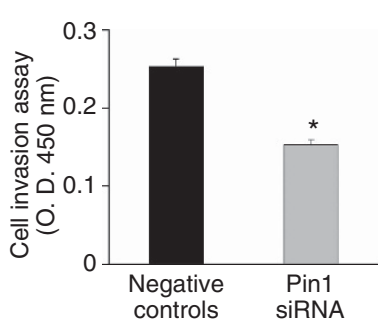

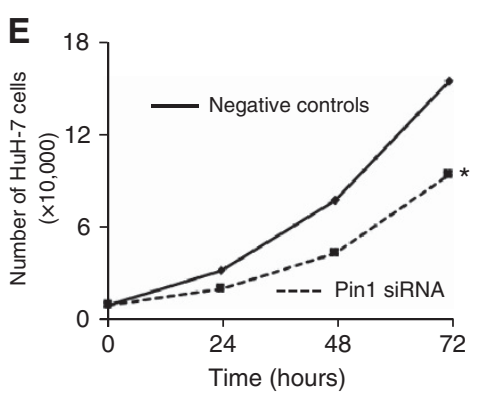
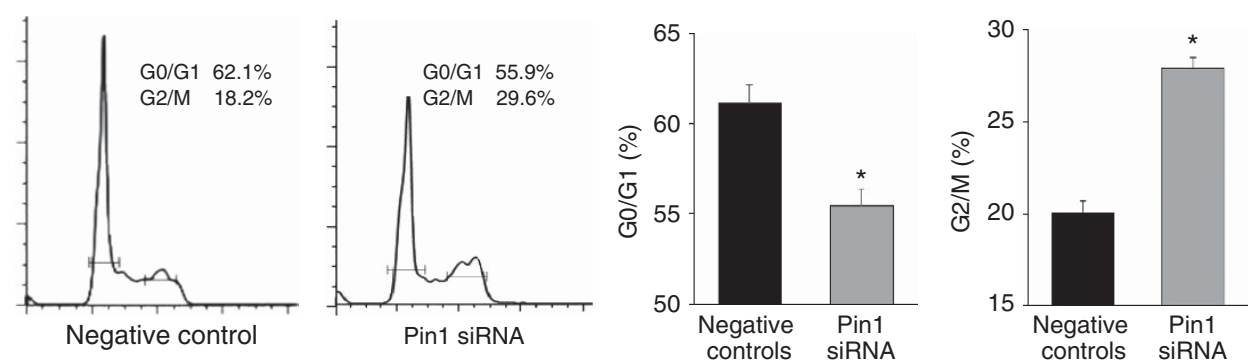

Figure 4. Effects of Pin1 siRNA knockdown in HepG2 cells in vitro. (A) Protein expression levels evaluated by western blotting. NF- $\kappa$ B activation was assessed by EMSA. Results were quantitated by image analysis of autoradiograms. Data are means \pm s.e.m. with $n=4-8$ per group. * $P<0.05$ compared with negative controls. (B) Cell cycle progression in HepG2 cells evaluated by DNA incorporation of BrdU. Data are means \pm s.e.m. with $n=12$ per group. ${ }^{*} P<0.01$ compared with negative controls at $48 \mathrm{~h}$ after incubation. (C) Effects of Pin 1 knockdown on HepG2 cell proliferation. Data are means \pm s.e.m. with $n=12$ per group. ${ }^{\star} P<0.01$ compared negative controls at $72 \mathrm{~h}$ after incubation. (D) Cell invasiveness in HepG2 cells evaluated by cell invasion assay. Data are means \pm s.e.m. with $n=12$ per group. ${ }^{*} P<0.01$ compared with negative controls at $48 \mathrm{~h}$ after incubation. (E) Effects of Pin1 knockdown on $\mathrm{HuH}-7$ cell proliferation. Data are means \pm s.e.m. with $n=12$ per group. ${ }^{*} P<0.01$ compared with negative controls at $72 \mathrm{~h}$ after incubation. (F) Cell cycle analysis in Pin1 knockdown HCC cells evaluated by flow cytometry. Pin 1 depletion increased G2/M accumulation, an indicator of cellular apoptosis, and decreased the population in the G1/G2 phase, which led HCC cells to cell cycle arrest with delayed mitotic entry. ${ }^{*} P<0.05$ compared with negative controls.

results, cell proliferation was inhibited in HepG2 cells with Pin1 knockdown (Figure 4C). Moreover, knockdown of Pin1 reduced the invasiveness of HepG2 cells after $48 \mathrm{~h}$ of treatment (Figure 4D). To confirm the effects of Pin1 knockdown on HCC cell proliferation, HuH-7 cells were further employed. In consistent with the results from HepG2, Pin1 knockdown in HuH-7 cells inhibited cell proliferation (Figure 4E). The results of cell cycle analysis showed that Pin 1 depletion decreased the population in 
the G1/G2 phase and increased the population in the G2/M phase, which led HCC cells to cell cycle arrest with delayed mitotic entry and to eventual apoptosis (Figure $4 \mathrm{~F}$ ).

Effects of the treatment with Pin1 inhibitor on HCC cell proliferation in vitro. To evaluate whether Pin 1 is a potential therapeutic target for HCC, HepG2 cells were treated with a Pin1 inhibitor, juglone. Juglone reduced the expression of $\mathrm{p}-\mathrm{NF}-\kappa \mathrm{B}-$ p65(Ser276), thereby inhibiting NF- $\kappa \mathrm{B}$ activation (Figure 5A). Moreover, DNA incorporation of BrdU was reduced in HepG2 cells after $48 \mathrm{~h}$ of treatment with $50 \mu \mathrm{M}$ juglone (Figure 5B). Consistent with these results, juglone inhibited HepG2 cell proliferation in a dose-dependent manner (Figure 5C). Inhibitory effects of juglone on HCC cell proliferation were confirmed using HuH-7 cells. Similar to the results from HepG2, HuH-7 cell proliferation was inhibited by juglone in a dose-dependent manner (Figure 5D). To evaluate whether these inhibitory effects of juglone were Pin1-specific, HCC cells were treated with another Pin1 inhibitor, $\mathrm{PiB}$. In consistent with juglone, $\mathrm{PiB}$ significantly inhibited tumour cell growth in HepG2 and HuH-7 in a dosedependent manner, suggesting that these anti-proliferative effects were mediated by Pin1 inhibition (Figures 5E and F).

\section{DISCUSSION}

In previous studies, Pin 1 has been reported to regulate NF- $\kappa \mathrm{B}$ signalling (Ryo et al, 2003; Atkinson et al, 2009) and promote tumour progression (Kuramochi et al, 2006) in several malignancies. With regard to HCC, a few studies have shown the mechanism by which Pin1 enhances hepatocarcinogenesis. However, the role of Pin1 in HCC progression remains unclear. The present study is the first to precisely examine the function of Pin1 on tumour progression in clinical cases of HCC.

At present, over 50 proteins have been identified as the target for Pin1 including the NF- $\kappa$ B-p65 (Lu and Zhou, 2007). We have previously shown that Pin 1 is important for hepatocyte NF- $\kappa \mathrm{B}$ activation during hepatic ischaemia/reperfusion (I/R) (Kuboki et al, 2007; Kuboki et al, 2009). In I/R model, NF- $\kappa \mathrm{B}$ is released after degradation of $\mathrm{I} \kappa \mathrm{B} \alpha$ during reperfusion. Pin 1 binds to released NF- $\kappa \mathrm{B}-\mathrm{p} 65$, protects it from degradation, and induces NF- $\kappa \mathrm{B}$ activation. However, the role of Pin 1 in NF- $\kappa \mathrm{B}$ activation in malignancies is quite different, as NF- $\kappa \mathrm{B}$ is constitutively activated even though abundant $\mathrm{I} \kappa \mathrm{B} \alpha$ exists in HCC (Tai et al, 2000). In the present study, we proposed a precise model of Pin 1 interaction with NF- $\kappa$ B in HCC (Supplementary Figure S1). Binding of Pin1 is essential for constitutive phosphorylation of NF- $\kappa$ B-p65(Thr254), as the p-NF- $\kappa \mathrm{B}-\mathrm{p} 65$ (Thr254) expression was decreased in HCC cells with Pin 1 knockdown. Therefore, in contrast to hepatic $I / R$, p-NF- $\kappa$ B-p65(Thr254) was dephosphorylated without Pin1, and $\mathrm{NF}-\kappa \mathrm{B}$ bound to $\mathrm{I} \kappa \mathrm{B} \alpha$ again to increase their stability. The mechanism of the phosphorylation of NF- $\kappa \mathrm{B}-\mathrm{p} 65$ (Thr254) is still unclear. As the binding site of $\mathrm{I} \kappa \mathrm{B} \alpha$ is close to Thr254 in NF- $\kappa \mathrm{B}$ $\mathrm{p} 65, \mathrm{I} \kappa \mathrm{B} \alpha$ might inhibit the phosphorylation of NF- $\kappa \mathrm{B}-$ p65(Thr254). It has been reported that $\mathrm{I} \kappa \mathrm{B}$ kinase (IKK) is strongly activated in malignant cells (Nakshatri et al, 2002). Therefore, separation from I $\kappa \mathrm{B} \alpha$ by IKK-induced $\mathrm{I} \kappa \mathrm{B} \alpha$ degradation enable NF- $\kappa$ B-p65(Thr254) to be phosphorylated, which mediates its binding to Pin1. In addition, knockdown of Pin 1 in HCC cells inhibited phosphorylation of NF- $\kappa$ B-p65(Ser276) and decreased activation of NF- $\kappa \mathrm{B}$. These findings suggest that binding of Pin 1 to p-NF- $\kappa$ B-p65(Thr254) induces phosphorylation of Ser276, thereby promoting nuclear translocation of NF- $\kappa \mathrm{B}$ and mediating its activation in HCC.

Pin1 is known as a key regulator of mitotic events by mediating the G1-S transition through regulating cyclins and cyclindependent kineses ( $\mathrm{Lu}$ et al, 1996; Ryo et al, 2002). Pin1 is reported to promote $\mathrm{HuH}-7$ cell growth via the upregulation of cyclin D1 and cyclin E (Farra et al, 2015). Moreover, NF- $\kappa \mathrm{B}$ activation is reported to induce G1-S transition through the downregulation of p27(kip1) by increasing Cks1 (Frau et al, 2012), as Cks1 mediates the ubiquitination of p27(kip1) which induces cell cycle arrest by inhibiting S phase entry (Ganoth et al, 2001). Knockdown of Pin 1 in human kidney cells is reported to increase the expression of p27(kipl), thereby promoting cell cycle progression (Brenkman et al, 2008). In contrast, another paper reported that Pin1 increased the stability of p27(kip1) and induced G2 arrest in fibroblast cells (Zhou et al, 2009). Therefore, regulation of Cks1-p27(kip1) pathway by Pin1 was still controversial. In the present study, we found that Pin1-induced HCC cell proliferation is mediated by increased expression of cyclin D1 and decreased expression of p27(kip1). The fact that cyclin D1 induces the degradation of 227 (kip1) by activating E2F, supports our findings. Pin1 seemed to mediate Cks1 expression; however, it might be regulated indirectly of Pin 1 through the microenvironment circumstance with cancer stromal tissue. In addition, we have revealed that Pin1 induces angiogenesis in HCC by increasing the expression of VEGF. As NF- $\kappa \mathrm{B}$ signalling induces angiogenesis by increasing the production of VEGF (Liu et al, 2010), angiogenesis induced by Pin 1 is also mediated by NF- $\kappa \mathrm{B}$ activation in HCC. Previous studies have shown that tumour invasiveness is remarkably increased in patients with high Pin1 expression in several malignancies (Matsuura et al, 2010); however, we have found no studies that report the association between Pin1 and tumour invasiveness in HCC in any experimental models. Our present study is the first to reveal the direct regulation of Pin 1 in HCC cell invasiveness. As Pin1 is reported to induce epithelialmesenchymal transition (EMT) in breast cancer (Kim et al, 2009), induction of EMT may be the key regulator of increased invasiveness in HCC with high Pin1 expression. Decreased expression of Pin1 is known to induce neuronal apoptosis and degradation in Alzheimer's disease (Lu et al, 1999). In the present study, we found that Pin1-induced G2/M cell cycle arrest and increased apoptosis in HCC in vivo and in vitro. As $\mathrm{NF}-\kappa \mathrm{B}$ signalling has anti-apoptotic effects and maintains cellular survival, Pin1-induced NF- $\kappa$ B activation plays a potent role in the inhibition of apoptosis in HCC.

We have also found that high Pin1 expression in HCC associates with large tumour size and positive portal vein invasion in clinical cases of HCC. The effects of Pin1 on cell cycle progression, angiogenesis, anti-apoptosis, and invasiveness through NF- $\kappa \mathrm{B}$ activation contribute to these findings. Given these results, we conducted that increased Pin 1 expression in HCC is an independent predictor for poor prognosis and early recurrence after hepatectomy. Therefore, close follow-up examinations are needed after operations in HCC patients with high Pin1 expression.

Finally, we sought to reveal whether Pin1 is a potential therapeutic target for HCC by employing famous Pin1 inhibitors, juglone and $\mathrm{PiB}$. Juglone is known to have some anti-cancer activity according to several studies in vitro (Henning et al, 1998). In HCC, only a study by Lee et al (2009) has demonstrated that juglone inhibits HCC tumourigenesis in vitro; however, the precise molecular mechanism is still unclear. Moreover, no studies have been conducted that show inhibitory effects of juglone on NF- $\kappa \mathrm{B}$ dependent cell proliferation in any malignant cells. Our present study shows direct inhibitory effects of juglone on Pin1-dependent phosphorylation of NF- $\kappa$ B-p65(Ser276) and activation of NF- $\kappa$ B. However, it is unclear whether these effects are Pin1-specific, as juglone potently inhibits several proteins and enzymes. Therefore, we confirm the effects of Pin 1 inhibition on tumour suppression by treatment with $\mathrm{PiB}$, as $\mathrm{PiB}$ is a synthesised drug which specifically inhibits Pin1. As complete knockdown of NF- $\kappa \mathrm{B}$ leads to embryonic lethality in mice, many anti-cancer therapies targeting 
A
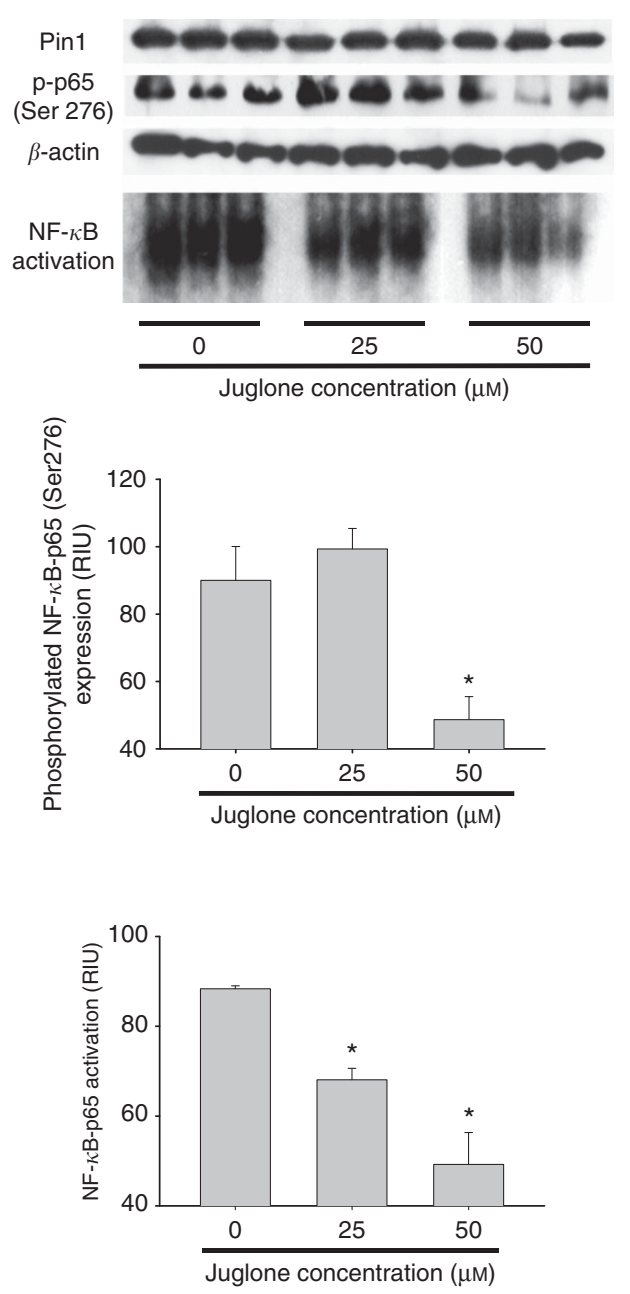

$E$

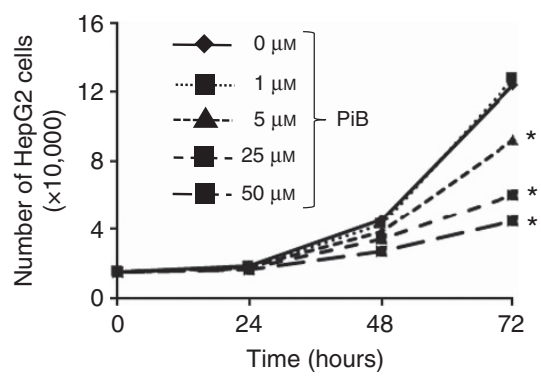

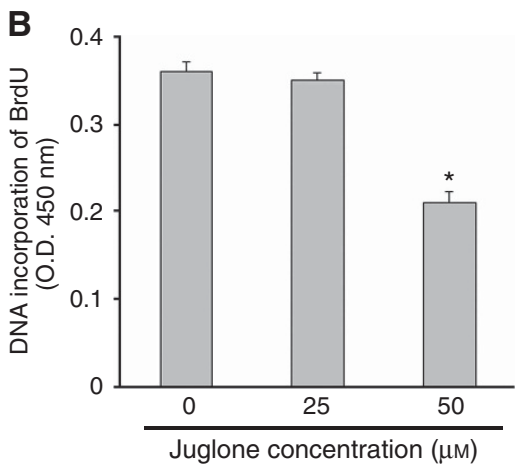
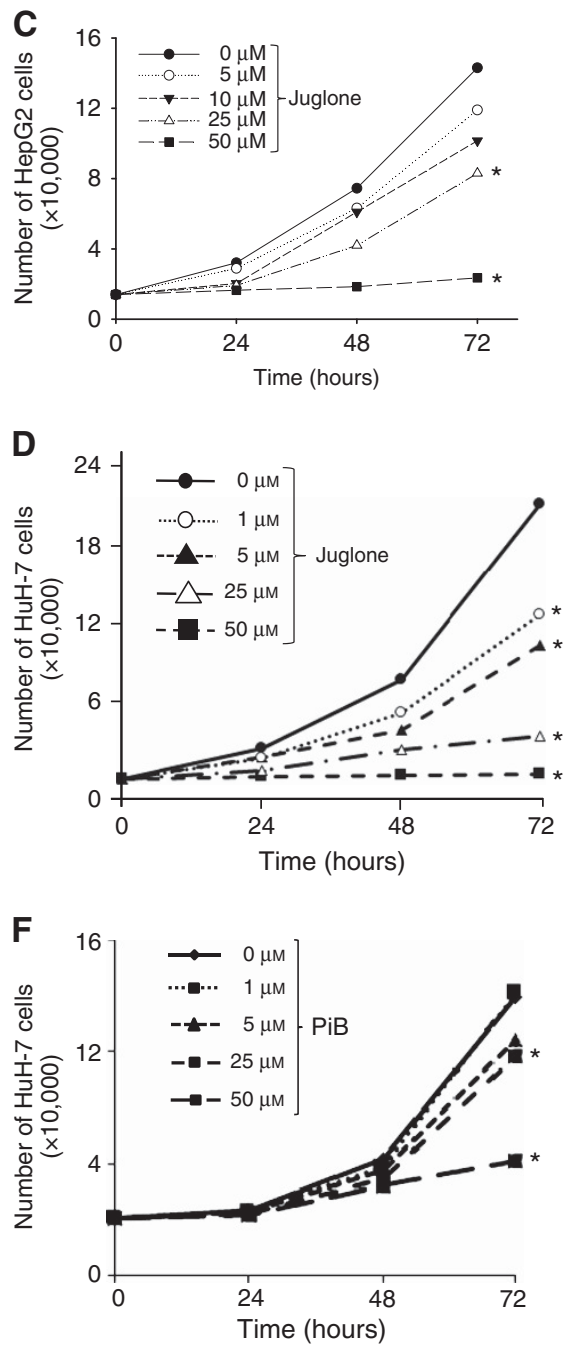

Figure 5. Effects of juglone treatment in HepG2 cells in vitro. (A) The expression of p-NF- $\kappa$ B-p65(Ser276) by western blotting and activation of NF- $\kappa$ B by EMSA were significantly inhibited in $\mathrm{HCC}$ cells treated with $50 \mu \mathrm{m}$ juglone. Results were quantitated by image analysis of autoradiograms. Data are means \pm s.e.m. with $n=9$ per group. ${ }^{\star} P<0.01$ compared with $0 \mu \mathrm{m}$. (B) Cell cycle progression in HepG2 cells evaluated by DNA incorporation of BrdU was significantly inhibited by $50 \mu \mathrm{m}$ juglone at $48 \mathrm{~h}$ after treatment. Data are means \pm s.e.m. with $n=12$ per group. ${ }^{\star} P<0.01$ compared with $0 \mu \mathrm{m}$. Effects of juglone treatment on cell proliferation in (C) HepG2 and (D) HuH-7 cells at $72 \mathrm{~h}$ after treatment. Data are means \pm s.e.m. with $n=12$ per group. ${ }^{*} P<0.05$ compared with $0 \mu \mathrm{m}$. Effects of PiB treatment on cell proliferation in (E) HepG2 cells and (F) HuH-7 cells at $72 \mathrm{~h}$ after treatment. Data are means \pm s.e.m. with $n=6$ per group. ${ }^{\star} P<0.05$ compared with $0 \mu \mathrm{M}$.

$\mathrm{NF}-\kappa \mathrm{B}$ failed because of severe adverse reactions. However, in conditions without Pin 1 , alternative cascades for NF- $\kappa$ B activation is slightly stimulated and maintains the minimal NF- $\kappa \mathrm{B}$ activation essential for the survival of normal organs. The fact that Pin1knockout mice are able to survive with slight activation of NF- $\kappa \mathrm{B}$, support these findings (Kuboki et al, 2009). We also need to pay attention to the side effects of Pin 1 inhibitors; however, we believe that Pin1 is a potential therapeutic molecular target for HCC by safely inhibiting NF- $\kappa \mathrm{B}$ activation. Further investigation and the development of a new drug-delivery system are needed for clinical application, by generating a xenograft mouse model of HCC cells with Pin1 overexpression and depletion.

In conclusion, Pin 1 overexpression is associated with aggressive tumour progression and poor prognosis in patients with HCC by 
mediating NF- $\kappa$ B activation. Therefore, Pin1 is a novel prognostic predictor and a potential therapeutic target for HCC.

\section{ACKNOWLEDGEMENTS}

This work was supported by JSPS KAKENHI Grant Number 26462036.

\section{CONFLICT OF INTEREST}

The authors declare no conflict of interest.

\section{REFERENCES}

Aigelsreiter A, Ress AL, Bettermann K, Schauer S, Koller K, Eisner F, Kiesslich T, Stojakovic T, Samonigg H, Kornprat P, Lackner C, Haybaeck J, Pichler M (2013) Low expression of the putative tumour suppressor spinophilin is associated with higher proliferative activity and poor prognosis in patients with hepatocellular carcinoma. Br J Cancer 108(9): 1830-1837.

Atkinson GP, Nozell SE, Harrison DK, Stonecypher MS, Chen D, Benveniste EN (2009) The prolyl isomerase Pin1 regulates the NF-kappaB signaling pathway and interleukin-8 expression in glioblastoma. Oncogene 28(42): 3735-3745.

Ayala G, Wang D, Wulf G, Frolov A, Li R, Sowadski J, Wheeler TM, Lu KP, Bao L (2003) The prolyl isomerase Pin1 is a novel prognostic marker in human prostate cancer. Cancer Res 63(19): 6244-6251.

Beg AA, Sha WC, Bronson RT, Ghosh S, Baltimore D (1995) Embryonic lethality and liver degeneration in mice lacking the RelA component of NF-kappa B. Nature 376(6536): 167-170.

Brenkman AB, de Keizer PL, van den Broek NJ, van der Grope P, van Diest PJ van der Horst A, Smits AM, Burgering BM (2008) The peptidyl-isomerase Pin1 regulates p27kip1 expression through inhibition of Forkhead box O tumorsuppressors. Cancer Res 68(18): 7597-7605.

Cheng CW, Chow AK, Pang R, Fok EW, Kwong YL, Tse E (2013) Pin1 inhibits apoptosis in hepatocellular carcinoma through modulation of the antiapoptotic function of surviving. Am J Pathol 182(3): 765-775.

El-Serag HB (2011) Hepatocellular carcinoma. N Engl J Med 365(3): 1118-1127.

Farra R, Dapas B, Baiz D, Tonon F, Chiaretti S, Del Sal G, Rustighi A, Elvassore N, Pozzato G, Grassi M, Grassi G (2015) Impairment of the Pin1/E2F1 axis in the anti-proliferative effect of bortezomib in hepatocellular carcinoma cells. Biochimie 112: 85-95.

Frau M, Tomasi ML, Simile MM, Demartis MI, Salis F, Latte G, Calvisi DF, Seddaiu MA, Daino L, Feo CF, Brozzetti S, Solinas G, Yamashita S, Ushijima T, Feo F, Pascale RM. (2012) Role of transcriptional and posttranscriptional regulation of methionine adenosyltransferases in liver cancer progression. Hepatology 56(1): 165-175.

Ganoth D, Bornstein G, Ko TK, Larsen B, Tyers M, Pagano M, Hershko A (2001) The cell-cycle regulator protein Cks1 is required for SCF(Skp2)mediated ubiquitinylation of p27. Nat Cell Biol 3(3): 321-324.

Henning L, Christner C, Kipping M, Rucknagel KP, Grabley S, Kullertz G, Fisher G (1998) Selective inactivation of parvulin-like peptidyl-prolyl cis/trans isomerases by juglone. Biochemistry 37(17): 5953-5960.

Kim MR, Choi HK, Cho KB, Kim HS, Kang KW (2009) Involvement of Pin1 induction in epithelial-mesenchymal transition of tamoxifen-resistant breast cancer cells. Cancer Sci 100(10): 1834-1841.

Kuboki S, Okaya T, Schuster R, Blanchard J, Denenberg A, Lentsch A (2007) Hepatocyte NF-kappaB activation is hepatoprotective during ischemiareperfusion injury and is augumented by ischemic hypothermia. Am J Physiol Gastrointest Liver Physiol 292(1): G201-G207.

Kuboki S, Sakai N, Clarke C, Schuster R, Blanchard J, Edwards MJ, Lentsch AB (2009) The peptidyl-prolyl isomerase, Pin1, facilitates NF-kappaB binding in hepatocytes and protects against hepatic ischemia/reperfusion injury. J Hepatol 51(2): 296-306.

Kuramochi J, Arai T, Ikeda S, Kumagai J, Uetake H, Sugihara K (2006) High Pin1 expression is associated with tumor progression in colorectal cancer. J Surg Oncol 94: 155-160.

Lee NY, Choi HK, Shim JH, Kang KW, Dong Z, Choi HS (2009) The prolyl isomerase Pin1 interacts with a ribosomal protein S6 kinase to enhance insulin-induced AP-1 activity and cellular transformation. Carcinogenesis 30(4): 671-681.

Liu LP, Liang HF, Chen XP, Zhang WG, Yang SL, Xu T, Ren L (2010) The role of NF-kappaB in Hepatitis $b$ virus $X$ protein-mediated upregulation of VEGF and MMPs. Cancer Invest 28(5): 443-451.

Lu KP, Hanes SD, Hunter T (1996) A human peptidyl-prolyl isomerase essential for regulation of mitosis. Nature 380(6574): 544-547.

Lu KP, Liou YC, Zhou XZ (2002) Pinning down proline-directed phosphorylation signaling. Trends Cell Biol 12(4): 164-172.

Lu KP, Zhou XZ (2007) The prolyl isomerase PIN1: a pivotal new twist in phosphorylation signalling and disease. Nat Rev Mol Cell Biol 8(11): 904-916.

Lu PJ, Wulf G, Zhou XZ, Davies P, Lu KP (1999) The prolyl isomerase Pin1 restores the function of Alzheimer-associated phosphorylated tau protein. Nature 399(6738): 784-788.

Matsuura I, Chiang KN, Lai CY, He D, Wang G, Ramkumar R, Uchida T, Ryo A, Lu K, Liu F (2010) Pin1 promotes transforming growth factor-beta-induced migration and invasion. J Biol Chem 285(3): 1754-1764.

Mitsuhashi N, Shimizu H, Ohtsuka M, Wakabayashi Y, Ito H, Kimura F, Yoshidome H, Kato A, Nukiu Y, Miyazaki M (2003) Angiopoietins and Tie-2 expression in angiogenesis and proliferation of human hepatocellular carcinoma. Hepatology 37(5): 1105-1113.

Nakshatri PB, Sweeney CJ, Nakshatri H (2002) Identification of signal transduction pathways involved in constitutive NF-kappaB activation in breast cancer cells. Oncogene 21(13): 2066-2078.

Pang R, Yuen J, Yuen MF, Lai CL, Lee TK, Man K, PoonRT, Fan ST, Wong CM, Nq IO, Kwong YL, Tse E (2004) PIN1 overexpression and beta-catenin gene mutations are distinct oncogenic events in human hepatocellular carcinoma. Oncogene 23(23): 4182-4186.

Pang R, Lee TK, Poon RT, Fan ST, Wong KB, Kwong YL, Tse E (2007) Pin1 interacts with a specific serine-proline motif of hepatitis B virus X-protein to enhance hepatocarcinogenesis. Gastroenterology 132(3): 1088-1103.

Pikarsky E, Porat RM, Stein I, Abramovitch R, Amit S, Kasem S, Gutkovich-Pyest E, Urieli-Shoval S, Galun E, Ben-Neriah Y (2004) NF-kappaB functions as a tumour promoter in inflammation-associated cancer. Nature 431(7007): 461-466.

Ryo A, Liou YC, Wulf G, Nakamura M, Lee SW, Lu KP (2002) Pin1 is an E2F target gene essential for Neu/Ras-induced transformation of mammary epithelial cells. Mol Cell Biol 22(15): 5281-5295.

Ryo A, Suizu F, Yoshida Y, Perrem K, Liou YC, Wulf G, Rottapel R, Yamaoka S, Lu KP (2003) Regulation of NF-kappaB signaling by Pin1-dependent prolyl isomerization and ubiquitin-mediated proteolysis of p65/RelA. Mol Cell 12(6): 1413-1426.

Tai DI, Tsai SL, Chang YH, Huang SN, Chen TC, Chang KS, Liaw YF (2000) Constitutive activationof nuclear factor kappaB in hepatocellular carcinoma. Cancer 89(11): 2274-2281.

The liver cancer study group of Japan (2011) The General Rules for the Clinical and Pathological Study of Primary Liver Cancer. Kanehara: Tokyo.

Zhou W, Yang Q, Low CB, Karthik BC, Wang Y, Ryo A, Yao SQ, Yang D, Liou YC (2009) Pin1 catalyzes conformational changes of Thr-187 in p27Kip1 and mediates its stability through a polyubiquitination process. J Biol Chem 284(36): 23980-23988.

This work is published under the standard license to publish agreement. After 12 months the work will become freely available and the license terms will switch to a Creative Commons AttributionNonCommercial-Share Alike 4.0 Unported License.

Supplementary Information accompanies this paper on British Journal of Cancer website (http://www.nature.com/bjc) 